\title{
Applying Human Rights-Based Approaches to Public Health: Lessons Learned from Maternal, Newborn and Child Health Programs
}

\author{
Allison Smith-Estelle ${ }^{1, a}$, Laura Ferguson ${ }^{b}$, and Sofia Gruskin ${ }^{b}$ \\ ${ }^{a}$ Concern Worldwide US and Keck School of Medicine, University of \\ Southern California, USA \\ ${ }^{\mathrm{b}}$ Keck School of Medicine and Program on Global Health and Human Rights, \\ Institute for Global Health, University of Southern California, USA
}

\section{Abstract}

The application of human rights norms at the national policy level is largely codified, but rigorous research on the field-level application of a human rightsbased approach (HRBA) to health programs is still in its infancy. The paper identifies human rights norms from international law and standards that are relevant to maternal, newborn and child health $(\mathrm{MNCH})$ programs, and presents an example of how a HRBA has been previously applied in an MNCH project. It introduces a HRBA framework recently developed by Concern Worldwide and partners, and conducts a document analysis of a previous Concern Worldwide project in Malawi. Discussion focuses on where and how the project could have benefited from incorporation of a HRBA in project design, implementation and evaluation. The authors conclude by discussing how such inclusion could have impacted project outcomes, and how such analysis can help inform future efforts to implement a HRBA to health.

Keywords: Health and human rights; Human rights-based approaches; Maternal, newborn and child health; Malawi

\section{Résumé}

L'application des normes en matière des droits de l'homme au niveau des politiques nationales est largement codifié, mais les recherches rigoureuses sur l'application de l'approche basée sur les droits de l'homme (ABDH) dans les programmes de santé est encore embryonnaire. Cet article identifie les normes en matière des droits de l'homme à partir du droit international qui sont pertinents pour les programmes de santé maternelle, néonatale et infantile (SMNI), puis présente un exemple de l'application de l'ABDH dans un projet de SMNI. II

\footnotetext{
${ }^{1}$ Corresponding author

Concern Worldwide US and Keck School of Medicine, University of Southern California. 808652-1908 (phone), allisonnepal@yahoo.com
} 
introduit un cadre conceptuel de l'ABDH qui a été récemment développé par Concern Worldwide et ses partenaires, et procède à une analyse documentaire à partir d'un projet de Concern Worldwide au Malawi. Les discussions mettent en exergue les occasions ou le projet aurait pu bénéficier de la prise en compte de I'ABDH dans la conception, la mise en œuvre ou l'évaluation. Les auteurs montrent finalement comment l'intégration de l'ABDH aurait influencé les indicateurs du projet, et comment une telle analyse permet d'informer les efforts futurs pour intégrer I'ABDH en santé.

Mots clés: Santé et droits de l'homme; Approches basées sur les droits de l'homme; Santé maternelle, néonatale et infantile; Malawi

\section{Introduction}

The application of human rights norms at the national policy level is well documented, but rigorous research focusing on the field level application of a human rights-based approach (HRBA) to health program design, implementation and evaluation, including measuring its impact on project outcomes, is still very much in its infancy. Below we identify human rights norms from international law and standards that are relevant to maternal, newborn and child health $(\mathrm{MNCH})$ programs, and to set the context for the rest of the paper provide a brief description of how a HRBA has been previously applied in Malawi. We then introduce a HRBA framework recently developed for Concern Worldwide's Innovations for Maternal, Newborn \& Child Health (Innovations) project, and retrospectively analyze a previous Concern Worldwide project in Malawi. Discussion focuses on where and how the project could have benefited from incorporation of a HRBA in project design, implementation and evaluation We conclude by discussing how such inclusion could have impacted project outcomes, and how such analysis can help inform future efforts to implement a HRBA to health.

\section{Methods}

We reviewed the English-language scholarly literature that identifies common elements of HRBAs. Our sources for institutional statements are primary websites of United Nations agencies and international nongovernmental organizations (NGOs) active in health. We also reviewed several sources of information from the Government of Malawi and Concern Worldwide for the document analysis, and engaged in formal and informal communications with Innovations project staff.

\section{Human Rights as They Relate to Health}

Every country has made human rights-based commitments that are relevant to maternal, newborn and child health, through the International Covenant on Economic, Social and Cultural Rights, the Convention on the Rights of the Child, the Convention to Eliminate All Forms of Discrimination Against Women and other treaties and conventions (United Nations Treaty Collection, 20/4). United Nations (UN) agencies have also made human 
rights commitments to guide their work. UNICEF's Mission Statement states that its work is guided by the Convention on the Rights of the Child (CRC), whose guiding principles include nondiscrimination; adherence to the best interests of the child; the right to life, survival and development; and the right to participate (UNICEF, 20I4). The United Nations Population Fund (UNFPA) frames its HRBA around the International Conference on Population and Development Programme of Action, stressing the importance of ensuring a gender-sensitive HRBA (UNFPA, 20I4). The World Health Organization (WHO) Constitution states "The enjoyment of the highest attainable standard of health is one of the fundamental rights of every human being without distinction of race, religion, political belief, economic or social conditions" (WHO, 20I4). Furthermore, the WHO commits to General Comment I4 of the Committee on Economic, Social and Cultural Rights, which provides programmatic substance to the right to the highest attainable standard of health (UN, 20I4), and uses the UN Statement of Common Understanding on Human Rights-Based Approaches to Development Cooperation and Programming definition framed around the right to health, highlighting availability, accessibility, acceptability, and quality of health facilities, goods and services (WHO, 20I4a).

Many national and international NGOs also explicitly integrate HRBA into their missions, guiding frameworks and programming. The International Planned Parenthood Federation (IPPF) stresses the importance of universal access to reproductive health information, education, and services (IPPF, 20I4), while the International
Save the Children Alliance recognizes children as rights holders and ensures their participation in development processes (Save the Children, 2014). CARE International's work is grounded in participation, non-discrimination, and accountability (CARE, 2014), while in 2008, Oxfam America and CARE USA together agreed on a list of 'essential elements' of HRBA, including participation, inclusion, and nondiscrimination (OXFAM 2008).

Despite impressive work to integrate human rights norms in policies at the international and national policy levels, very little rigorous and documented research focusing on the field-level application of HRBA to maternal, newborn and child health program design, implementation and evaluation, including measuring its impact on project outcomes, exists (WHO, 2014a). While clarity and agreement about methods and tools to carry out such research is still forthcoming, several criteria have emerged as critical to an HRBA, including: considering the legal and policy context within which interventions occur; supporting the participation of affected groups, especially traditionally disadvantaged groups, in all efforts that concern them; working to ensure discrimination does not occur in the delivery of services nor in the health outcomes experienced among different population groups; using human rights standards to deliver services in particular with respect to ensuring their availability, accessibility, acceptability and quality; and ensuring transparency and accountability both for how relevant decisions are made and their ultimate impact (Gruskin et al, 2008). 
The following human rights are commonly considered key to a HRBA to health by scholars and practitioners.

\section{Right to Health (WHO, 2002)}

The right to health is defined as the right of everyone to the enjoyment of the highest attainable standard of physical and mental health. Because many social and economic factors affect the potential for people to be as healthy as possible, the realization of the right to health is dependent on and related to many other human rights. Four key elements of the right to health are further articulated below.

Availability. Functioning public health and health care facilities, goods, services and programs have to be available in sufficient quantity and must include underlying determinants of health (such as safe and potable drinking water and adequate sanitation facilities), hospitals, clinics and other health-related buildings, trained and fairly paid medical and professional personnel, and essential drugs.

Accessibility. Health facilities, goods, and services have to be physically and economically accessible to everyone without discrimination, within the jurisdiction of the State party.

Acceptability. Health facilities, goods and services must be respectful of medical ethics and culturally appropriate, sensitive to gender and life-cycle requirements, and designed to respect confidentiality and improve the health status of those concerned.

Quality. Health facilities, goods and services must be scientifically and medically appropriate and of good quality.
Participation (WHO, 2002)

The principle of participation is to ensure free, meaningful and effective participation of beneficiaries of health development policies or programs in decision-making processes which affect them.

\section{Accountability (WHO, 2010)}

Accountability mechanisms should exist at local, national, regional and international levels to monitor compliance and support governments in fulfilling their human rights obligations. Any person or group who considers themselves to be victim of a violation of the right to health should have access to effective judicial or other appropriate remedies.

\section{Non-Discrimination (UNICEF, 20I2)}

Non-discrimination means that all rights holders should be treated equally, with no discrimination in access to health care and underlying determinants of health, as well as to means and entitlements for their procurement on the grounds of race, color, sex, language, religion, political or other opinion, national or social origin, property, birth, physical or mental disability, health status, sexual orientation and civil, political, social or other status, which has the intention or effect of nullifying or impairing the equal enjoyment or exercise of the right to health.

\section{Previous Application of HRBA in} Malawi at the MNCH Program Level WHO and UNICEF designed the Community Integrated Management of Childhood Illnesses (C-IMCl) approach in Malawi in the 1990s to address the "disproportionate share of the disease 
burden falling on children under 5 years" (Government of Malawi, 2003) and to "give effect to the articles of the United Nations Convention on the Rights of the Child that deal with the right to health and health care" (WHO Regional Office for Africa, 2014). Malawi's adoption and application of the C-IMCl policy "aimed to reduce child morbidity and mortality and enhance child development by increasing access, coverage, and utilization of promotive, preventive and basic essential services for maternal, neonatal and child health" (Government of Malawi, 2003).

While $\mathrm{C}-\mathrm{IMCl}$, implemented by UNICEF-Malawi and its partners, preceded the formal articulation of a HRBA, the project adopted tools that are complementary to a HRBA. The first was a community dialogue tool, which stresses the importance of iterative, transformative processes based on dialogue between health workers and community members. Through dialogue, it is hoped that community health workers become more accountable for their services and more receptive to input from the community, and that community members increasingly value, and access, the services provided (Zimba et al, 2012). While the community dialogue tool emphasizes effectiveness and feasibility rather than the enjoyment of human rights per se, and while its focus is on the entire community rather than identified human rights duty bearers and rights holders, it emphasizes the human rights concepts of participation and equality (WHO, 2013). C-IMCl also adopted a care group methodology, which brings health information and support services to communities through networks of community volunteers (Zimba et al, 20I2). Small groups of women meet in a care group to discuss effective healthpromoting practices with a trained health educator and are responsible for then sharing this knowledge with neighbours. Through the use of these methodologies, several human rights norms, including community participation, accountability, and the accessibility and acceptability of services have been introduced.

Several issues arose during C-IMCl implementation. Requested financial contributions for community-based drug revolving funds proved too costly for many community members, and many communities complained that the funds were fundamentally discriminatory, as communities nearer to health facilities received drugs free of charge. Another issue that raised discrimination concerns was the distribution of bed nets. Community members questioned why only pregnant women or those with young children received heavily subsidized bed nets, rather than those who had not yet started childbearing or those who practiced family planning and therefore prevented births. Finally, although the community dialogue tool was fundamentally aligned with human rights norms, its actual use still saw health workers largely telling community members what to do rather than engaging in dialogue as equals (Government of Malawi, 2003).

Despite some implementation concerns, key child health indicators improved greatly over the course of CIMCl implementation. Neonatal mortality rates dropped an average of $3.5 \%$ each year, while under- 5 mortality rates dropped by an average of $4.4 \%$ annually (UNICEF et al, 20II). Vaccination coverage rates increased substantially and grew more quickly in rural than in urban areas, indicating that 
rural outreach was strong. Antenatal care attendance increased, while the rate of deliveries at a health facility increased from $55 \%$ to $73 \%$ (Malawi DHS, 2010). Beyond quantitative indicators, HRBA evaluation results indicated that communities internalized the human rights concept of duty bearers and rights holders. The attitudes of service providers (duty bearers) improved, while community members, in order to facilitate greater participation and accountability, created new committees, where both men and women participated and served as additional community-level duty bearers (Government of Malawi, 2003). Project evaluations suggest that attention to these human rights concerns in shaping $\mathrm{C}-\mathrm{IMCl}$ not only had a positive impact on health, but also transformed relationships between health providers and community members, empowered the community, and improved individuals' quality of life (WHO, 20I3). Since the inception of this project, Malawi has participated in a number of HRBA efforts to improve maternal and child health.
Concern Worldwide's HRBA

Framework for MNCH

Concern Worldwide, with funding from the Bill \& Melinda Gates Foundation, is implementing Innovations for Maternal, Newborn \& Child Health (Innovations) in several countries. Innovations develops and tests innovative interventions and strategies that can address common barriers to improving coverage of basic $\mathrm{MNCH}$ services, including antenatal and postnatal care, facility-based deliveries, breastfeeding, childhood vaccinations and others.

In its second phase of experimentation and learning, Innovations is applying a HRBA to its project and research designs. Drawing from major UN frameworks and with inputs from UNICEF and external experts, Innovations developed its HRBA framework around four human rights norms: the right to health, participation, accountability and non-discrimination. These four human rights norms, and many of the corresponding lines of inquiry as presented in Table I, guided the retrospective analysis of an earlier Malawi-based Innovations' project, presented below.

\section{Table I. HRBA Norms and Innovations' Project Design and Research Questions}

\begin{tabular}{|ll|}
\hline Right to Health & Are laws, policies and interventions relevant to the project consistent with \\
international human rights norms and standards? \\
- Can the national policy environment help frame/support project activities? Is \\
it problematic in any way? \\
- What mechanisms are in place to determine the degree to which existing \\
relevant goods, services and information are provided in a manner that is \\
available, accessible, and acceptable and of high quality? \\
- How will the project capture client perspectives on the availability, \\
accessibility, acceptability and quality of its interventions?
\end{tabular}




\begin{tabular}{|c|c|}
\hline & $\begin{array}{l}\text { - How will meaningful participation of different stakeholders be monitored } \\
\text { and evaluated? }\end{array}$ \\
\hline Accountability & $\begin{array}{l}\text { - For all services and interventions, including those provided by the } \\
\text { government, are there monitoring, claims and redress mechanisms in place } \\
\text { and accessible? } \\
\text { - How will impediments to accountability be identified and addressed in the } \\
\text { situation analysis and review processes? } \\
\text { - What mechanisms is the project putting in place to ensure transparency in } \\
\text { decision-making and accountability of all stakeholders? } \\
\text { - How will clients' comments and complaints be documented, including the } \\
\text { outcomes arising from any such comments/complaints? }\end{array}$ \\
\hline $\begin{array}{l}\text { Non- } \\
\text { discrimination }\end{array}$ & $\begin{array}{l}\text { - Do policies refer to specific excluded populations? In what ways? What } \\
\text { impact might this have on project efforts to ensure non-discrimination? } \\
\text { - How will considerations of non-discrimination and equality of rights-holders } \\
\text { be integrated into programs and services, and taken into account throughout } \\
\text { the project cycle? } \\
\text { - Do assessments of marginalization and vulnerability take into account the } \\
\text { analysis of data disaggregated by, as relevant, race, color, ethnicity, gender, } \\
\text { religion, language, political, disability, nationality, birth, or other status, and } \\
\text { other bases of discrimination? }\end{array}$ \\
\hline
\end{tabular}

A Retrospective Analysis of

\section{Innovations' Previous Work in Malawi}

\section{Project Background and Design}

As demonstrated above, Malawi has a long standing commitment to the application of HRBAs to maternal and child health programming. In Balaka District, Malawi, the average village is over six kilometers from a health center. There has traditionally been a severe shortage of qualified medical personnel to provide minimum standards of service delivery; when there was an emergency at night or on weekends, staff often refused to see the patient, and some staff were reported to be rude and abusive, both verbally and, on occasion, physically (Invest in Knowledge Initiative Baseline Report 20II). Clinics opened late, there were long lines, and it was not uncommon for those who had not been seen by lunchtime to be told to return the next day. Accountability in the health sector was limited: regulations were not enforced, and even when physical abuse led to a miscarriage or a death, the only punishment appears to have been to transfer the staff member to another health center (NORAD 20I2).

The Innovations Information and Communications Technology for Maternal, Newborn and Child Health (ICT for $\mathrm{MNCH}$ ) project was designed to bridge the divide between communities in Balaka District and lifesaving health and information services by providing pregnant women and caregivers of young children with new, timely, and reliable means of accessing $\mathrm{MNCH}$ information. With the guiding philosophy that communities know their needs best, and that innovative ideas for health could come not only from people in the health sector but from people in other sectors, Innovations began its work by introducing a nationwide campaign to generate suggestions for projects. Project staff encouraged widespread participation by specifically soliciting suggestions from rural residents, and pairing illiterate individuals with scribes to capture their ideas. Several thousand suggestions were submitted by the 
public, then assessed by panels of experts; a hotline and a clinic booking system were the two ideas chosen. Innovations designed the preliminary project structure to incorporate both ideas, but due to concerns among nurses and technological constraints, the booking system was never fully implemented.

The toll-free case management hotline was designed to provide protocol-based health information, as well as advice and referrals for pregnant women, caretakers of children under one year of age and women of childbearing age. Hotline users were also to receive calls or text messages with tips on appropriate care seeking and health practices. It was hypothesized that these interventions would lead to increased awareness of appropriate facility and home-based interventions among pregnant women and caregivers of young children, as well as improved community perceptions of the quality of $\mathrm{MNCH}$ care, and that there would be an increased uptake of appropriate home and facility-based $\mathrm{MNCH}$ practices and reductions in neonatal and child mortality (Invest in Knowledge Initiative, 2013).

The project design included training female and male community volunteers (CVs) to disseminate information about the hotline to women in their communities in order to generate user demand, and providing CVs with mobile phones to ensure community members' equitable access to the hotline. A woman who wanted to use the hotline would either use her own phone or go to a community volunteer, who was instructed to dial the hotline number, and then leave the client to talk privately with the hotline worker. Phone calls were recorded, which permitted a supervising nurse to assess whether hotline workers were responding appropriately, but callers were not informed that the calls were being recorded.

The monitoring and evaluation design consisted of several quantitative and qualitative methods, including a quasiexperimental, pre-test and post-test with purposive sampling; questionnaires focusing on household characteristics, as well as women's and under-five children issues; focus group discussions; in-depth interviews; key informant interviews; ethnographies; and rapid facility assessments.

\section{Project Implementation}

As is common as new projects evolve, project staff learned important lessons once implementation began. A fundamental challenge was the use of CVs. While community-based Health Surveillance Assistants (HSAs) have been salaried members of Malawi's health workforce for decades and are trained to provide first-line treatment for some childhood illnesses, this project introduced $\mathrm{CVs}$ as a new actor to implement project work. HSAs, who were tasked with recruiting and supervising $\mathrm{CVs}$, expressed frustration that they received no payment for their efforts and had been largely bypassed by the project, both in terms of receiving training and phones. This perceived breach of protocol was described as such:

...it appeared that our HSAs who were working in the communities were jealous because a volunteer cannot be honored with a phone while 'l, a captain of health issues in this village, do not even have a phone.' Volunteers were making people 
think that the HSAs had no value because they didn't have a phone (District Information, Education and Communication officer, Invest in Knowledge Initiative, 2013).

Project staff also received reports that CVs were acting as gatekeepers by controlling access to services, listening in on phone calls, asking women about the outcome of their hotline calls, and providing medical advice for which they had insufficient training.

In addition, CVs were not initially paid for their work, which was widely seen as unsustainable and unfair, and appeared to impact the amount of effort CVs gave to the project. While they were eventually paid, this oversight impacted goodwill and project quality.

...the volunteers were not properly considered...They leave their responsibilities rushing to the house of a subscriber when tips and reminders come. Sometimes, they leave their work attending to a woman who wants to use the phone...HSAs (were asked) to get someone who can at least read and write, who can operate a phone, so they said "you said you wanted an individual who was knowledgeable about the use of a phone, and who can write and read...but you are just giving us a milk-scone and fanta" (HSA commenting on CVs, Invest in Knowledge Initiative, 20I3).

\section{Project Outcomes}

Evaluation data indicated that users found the hotline convenient and easy to use, and hotline workers respectful. Users also reported that hotline use led to better treatment at the health facilities. One user reported that "It's good to call the hotline first... because you can find that there are no drugs...we (could) be wasting time walking to the health center." Furthermore, there was a perception among hotline users that if you called the hotline, the health center staff would treat you better. One woman expressed that "When you tell health facility staff that you talked to (a hotline) worker, there is now a difference in the sense that this time you are given proper medicine while the same people had failed to treat you properly earlier on." Health care workers also report encouraging changes in behaviors due to the hotline.

In the past we used to get women who are five months pregnant...now we are receiving women with a few months old pregnancy. And sometimes we could ask them 'what has happened for you to come with a few months pregnant like this?' They say 'we called on the hotline and we have been told what to do' (Invest in Knowledge Initiative, 20I3).

Among women who took advantage of the program's services, there was a positive effect on home-based practices at the level of the individual woman, especially in reported use of bed nets during pregnancy and in breastfeeding within one hour of birth. There was also a positive effect on antenatal care attendance in the first trimester and a small increase in postnatal care checkups within two days of birth.

While these results were encouraging, others were concerning. Monitoring data indicated that hotline workers resolved the majority of calls without referring callers to a health facility, but no data were collected to assess the prevalence of misdiagnosis, nor on whether callers who were referred actually went to the clinic or not. In hindsight, these missing data were critical, as evaluators found a large and negative effect on use of facility- 
based services for child health ( 45 percentage points) among children whose caretakers used the hotline. Evaluators expressed concern about this "reduction in the rate at which children in the intervention communities with symptoms of acute respiratory infection or fever access facility services" (Invest in Knowledge Initiative, 2013).

Survey data indicated that hotline adopters were different from nonadopters in several important ways. The number of years of education a woman had completed was positively correlated with using the hotline, as was household ownership of a mobile phone. Furthermore, phone literacy for women who did not own their own phones proved to be a challenge in terms of accessing project information (Crawford, 2014). Ownership of a mobile phone took on even greater significance as the project progressed, as poor quality phones led the project to relying more heavily on women using their own phones to access the hotline. Additional qualitative user insights were limited, as focus group discussion participants were not separated by age, socio-economic status, ethnic group or other characteristics. Project evaluators admitted that "it is likely that the focus group discussions reflect the opinion of the more talkative women, who may differ in other relevant characteristics from the quieter women" (Invest in Knowledge Initiative, 2013).

Finally, geographic location impacted knowledge of, and therefore participation in, the project. Every additional health worker per 10,000 people increased the likelihood of knowing about the project by $84 \%$.

\section{Discussion: Analyzing the Project using a HRBA Framework}

Table 2 lists the components of project design, monitoring and evaluation design, implementation and outcomes in the order introduced above and analyzes them vis-à-vis the four human rights norms included in Innovations' HRBA framework: the right to health, participation, accountability and nondiscrimination. The components in bold are those that successfully addressed human rights. 
Table 2. HRBA Analysis of MNCH Project

\begin{tabular}{|c|c|c|c|c|c|c|c|}
\hline & \multicolumn{4}{|c|}{ Right to Health } & \multirow[b]{2}{*}{ 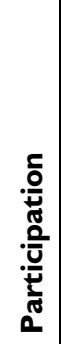 } & \multirow[b]{2}{*}{ 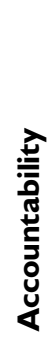 } & \multirow{2}{*}{ 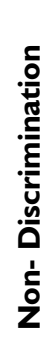 } \\
\hline & 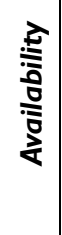 & 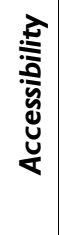 & 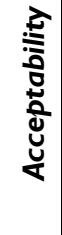 & 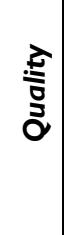 & & & \\
\hline Widespread participation during project design phase & & $\mathrm{X}$ & & & $\mathrm{x}$ & & $\mathrm{x}$ \\
\hline $\begin{array}{l}\text { Strong outreach to rural and illiterate populations during } \\
\text { project design phase }\end{array}$ & & $x$ & & & $x$ & & $\mathrm{x}$ \\
\hline $\begin{array}{l}\text { Having men serve as Community Volunteers for women's health } \\
\text { project }\end{array}$ & & $\mathrm{x}$ & $\mathrm{x}$ & & $x$ & & \\
\hline Not obtaining informed consent to record hotline calls & & & $\mathrm{X}$ & & & $\mathrm{X}$ & \\
\hline HSAs feelings largely bypassed by project & & & & $\mathrm{X}$ & $x$ & $\mathrm{X}$ & \\
\hline $\begin{array}{l}\text { HSAs admitting to not helping Community Volunteers as } \\
\text { requested }\end{array}$ & & $\mathrm{x}$ & $\mathrm{X}$ & $\mathrm{X}$ & $x$ & $\mathrm{X}$ & \\
\hline Community Volunteers acting as gatekeepers of information & & $\mathrm{x}$ & & $\mathrm{X}$ & $x$ & $x$ & \\
\hline $\begin{array}{l}\text { Community Volunteers giving medical advice without sufficient } \\
\text { knowledge }\end{array}$ & & & & $\mathrm{X}$ & & & \\
\hline Community Volunteers not being paid & & & & $\mathrm{X}$ & & & \\
\hline $\begin{array}{l}\text { Users reporting hotline convenient and easy to use, } \\
\text { hotline workers respectful }\end{array}$ & $\mathrm{X}$ & $\mathrm{x}$ & $x$ & $x$ & $\mathrm{X}$ & & \\
\hline $\begin{array}{l}\text { Hotline use leading to better home based / facility based } \\
\text { practices for women }\end{array}$ & $\mathrm{X}$ & $x$ & $x$ & $\mathrm{X}$ & $x$ & & \\
\hline $\begin{array}{l}\text { No data collected about misdiagnosis / whether callers went to } \\
\text { clinic when referred }\end{array}$ & & & & $\mathrm{X}$ & & & \\
\hline $\begin{array}{l}\text { Limited consideration of socio-economic context of potential } \\
\text { project participants }\end{array}$ & & & & & $\mathrm{x}$ & & $x$ \\
\hline Low education levels and literacy levels & & $\mathrm{x}$ & & & $x$ & & $x$ \\
\hline No mobile phone ownership & & $x$ & & & $x$ & & $x$ \\
\hline Participants' limited use of / familiarity with mobile phones & & & $x$ & & $x$ & & $x$ \\
\hline Poor quality phones & $x$ & $\mathrm{x}$ & & & $x$ & & $x$ \\
\hline Decision not to separate women for focus groups & & & & & $x$ & & \\
\hline Geographic location /isolation & & $\mathrm{X}$ & & & $x$ & & $\mathrm{x}$ \\
\hline
\end{tabular}


The project addressed key elements of the right to health (availability, accessibility, acceptability and quality), as women who used the hotline reported that hotline workers were respectful and that the hotline was easy and convenient to use. Furthermore, evaluators found improved home-based practices and facility-based practices for hotline users, which demonstrates a fulfillment of the right to health.

Participation was addressed in a number of ways, including through the intensive engagement of community members in the design phase of the project. Efforts to engage rural and illiterate members of the community demonstrates commitment to the human rights norm of nondiscrimination.

Despite the successful application of human rights norms described above, our analysis demonstrates that there were many instances where the project could have benefitted from the use of a HRBA. Conscious application of a HRBA framework during early design work would have highlighted the need to consider socio-economic differences among potential project participants and plan accordingly. Project data clearly showed that education and literacy levels as well as household ownership of a mobile phone and previous exposure to mobile phone technology impacted women's participation, with additional implications for health availability and acceptability as well as nondiscrimination.

The fact that the project used poor quality phones, many of which quickly fell into disrepair and therefore shifted project emphasis to women who could use their own phones, increases concern about health availability and accessibility, as well as participation and non-discrimination. Data showing that women in areas with fewer health workers reported less knowledge of the project indicate that geographic location impacts health accessibility, participation and non-discrimination.

Several of the noted staffing issues were inconsistent with application of human rights norms to programming, including CVs controlling access to services, listening in and asking women about the outcome of their hotline calls, and providing advice for which they had insufficient medical training. These issues have potential impacts on health accessibility and quality, raise concerns about basic medical confidentiality (which could impact participation), and accountability. That volunteers were not initially paid for their work nor received other benefits could have also impacted health quality and accountability, while the fact that HSAs (who are a cornerstone of the Malawi public health system) reported being largely bypassed by the project, raises health quality, participation and accountability concerns.

\section{Conclusions}

While it is not possible to definitively show how project outcomes were impacted by not applying HRBA to this project, several data points allow us to speculate about what might have happened had a HRBA been used during the life of the project. As previously described, project data showed that hotline use led to better home-based and facility-based practices among women. Common sense tells us that other women would have likely adopted such practices as well had they used the hotline, but barriers, including lower 
education and literacy skills, nonownership of a mobile phone and other socio-economic variables, prevented them from participating. Had these socio-economic issues been acknowledged and steps pre-emptively taken to address them in the project design phase, a wider range of women may have participated and benefitted from the project.

The monitoring and evaluation design phase of the project did not include mechanisms to explore whether hotline misdiagnosis was an issue, nor was there a way to track whether a hotline caller referred to a clinic ever went for her appointment. While there is no way to know the breadth of misdiagnosis or missed appointments or the resulting health impacts, both point to potential issues that could have been addressed using a HRBA.

This paper demonstrates that a retrospective analysis is a useful first step for highlighting the potential for application of a HRBA to all phases of projects, from project conceptualization and design, to implementation, monitoring and evaluation. The analysis presented demonstrates the benefits a HRBA can have across all stages of the project cycle.

Given the wide range of organizations globally that have stated commitments to a HRBA to health, analyses that provide insight into how such approaches might be applied to health programming, and the difference they can make, are essential. Applying a HRBA can uncover design and implementation issues that can impact individuals' access to a health intervention being introduced, affect their willingness to accept a project and actively participate in its execution, or demonstrate potential violations of rights. Finally, a HRBA expands the universe of outcomes by which to measure success, by considering not only traditional, quantitative public health outcomes, but also those focused on human rights norms that show disparities and gaps in service provision, as well as opportunities for greater inclusion. This work is a necessary step towards determining the ways in which a HRBA can be most useful to improving maternal, newborn and child health, and the ways in which rights can be used in programming to improve awareness, the ways services are delivered, and ultimately enhance and contribute to health and well-being.

\section{Acknowledgements}

The Innovations for Maternal, Newborn \& Child Health, an initiative of Concern Worldwide U.S., is funded through a multi-year grant from the Bill \& Melinda Gates Foundation. The Government of Norway and the United Nations Foundation also supported the Malawi mHealth project (CCPF) through the Innovation Working Group Catalytic mHealth Grants program as part of the UN Secretary General's Every Women Every Child strategy. We would like to give special thanks to the Reproductive Health Unit and its Director, Mrs. Fannie Kachale, and the Balaka District Health Office for their support of CCPF. Our thanks to Dr. Kumanan Rasanathan, Senior Health Specialist at UNICEF, Dr. Mila Rosenthal, Director of Communications at United Nations Development Program (UNDP), Dr. Jean Christophe Fotso, Associate Director for Research, Monitoring \& Evaluation at Concern Worldwide USA, for providing comments on the research design, the paper's outline and the drafts 
of the manuscript, and to other Concern Worldwide staff members for their valuable insights and assistance. We acknowledge the comments from the anonymous reviewers.

\section{Authors' Contributions}

All authors contributed significantly to the conceptualization, design and analysis of this work, as well as to the drafting, writing and revision of the paper.

\section{References}

CARE, 2014. Incorporation of a rightsbased approach into CARE's program cycle: A discussion paper for CARE's program staff, http://pqdl.care.org/CuttingEdge/Inco rporating\%20RBA\%20in\%20CARE's \%20Program\%20Cycle.pdf, [accessed on 29 September 2014].

Crawford, Jessica. Emai correspondence with VillageReach staff, September 3, 2014

Government of Malawi, 1995. Malawi Constitution, http://www.sdnp.org.mw/constitut/dt lindx.html [accessed on 29 September 2014].

Government of Malawi, 2002. Malawi Poverty Reduction Strategy Paper, 2002-2006.

Government of Malawi, 2003. A Malawi HRAP C-CIMCI Case Study.

Government of Malawi, 2006. Malawi Growth and Development Strategy, 2006-201I.

Government of Malawi, 2007. Five Year National Strategic Plan for Accelerated Child Survival and Development in Malawi: scaling up high impact interventions in the context of Essential Health Package, 2007-20II.

Government of Malawi, 20II. Ministry of Health, Health Sector Strategic Plan 20I I-2016.

Gruskin S, and Tarantola D, 2008. "Universal access to HIV prevention, treatment and care: assessing the inclusion of human rights in international and national strategic plans.” AIDS 22: SI 23-32

Gruskin S, Bogecho D and Ferguson L, 2010. "Rights-based approaches to health policies and program: Articulations, ambiguities, and assessment": Journal of Public Health Policy 31, (2): I 29- I 45

International Planned Parenthood Federation, 2014. Strategic framework 2005-2015, http://www.ippf.org/en/Resources/Re ports

reviews/Strategic +Framework +200

5-20I5.htm, [accessed on 29 September 2014].

Invest in Knowledge Initiative, 201I. Baseline Report for an Evaluation of Information and Communications Technology to Improve Health Services for Mothers and Children Project, Malawi.

Invest in Knowledge Initiative, 2013.

Evaluation of the Information and Communications Technology for Maternal, Newborn and Child Health Project, Malawi.

Malawi Demographic and Health Survey, 2010.

http://www.nsomalawi.mw/images/st ories/data_on_line/demography/MD HS2010/MDHS2010\%20report.pdf [accessed on 29 September 2014].

NORAD, 2012. Evaluations

Department. Local perceptions, 
participation and accountability in Malawi's Health Sector.

Oxfam America and CARE USA, 2008. Rights-Based Approaches Learning Project. Boston, MA: Oxfam.

Save the Children, 2014. Our Vision, Mission and Values, http://www.savethechildren.net/abou t-us/our-vision-mission-and-values, [accessed on 29 September 2014].

UNDP, 2013. Malawi Human Development Index, http://hdr.undp.org/sites/default/files/ Country-Profiles/MWI.pdf [accessed on 29 September 2014].

UNFPA, 2014. The human rights-based approach, http://www.unfpa.org/rights/approac hes.htm [accessed on 29 September 2014].

UNICEF et al, 20II. Levels and trends in child mortality report $20 \mathrm{I} \mathrm{I}$.

UNICEF, 20I2. "Global Evaluation of the Application of a Human Rights Based Approach to UNICEF Programming"

http://www.unicef.org/policyanalysis/ rights/files/UNICEF_HRBAP_Final_R eport_Vol_I_I IJune_copyedited_translated.pdf [accessed on 29 September 2014].

UNICEF, 2014. UNICEF Mission Statement,

http://www.unicef.org/about/who/ind ex_mission.html [accessed on 29 September 2014].

UNICEF, 2014a. Malawi records tremendous gains in reducing under five deaths, http://www.unicef.org/esaro/5440_m alawi_under5.html [accessed on 29 September 2014].

UNICEF, 20l4b. Malawi basic indicators. New York, United Nations Children's Fund (http://www.unicef.org/malawi/MLW _children_indicators.pdf). [accessed on 29 September 2014].

United Nations, 2014. Committee on Economic, Social and Cultural Rights, Report on the Twenty-Second, Twenty-Third and Twenty-Fourth Sessions,

http://www.un.org/documents/ecosoc/d ocs/200I/e200I-22.pdf [accessed on 29 September 2014].

United Nations Treaty Collection, 2014. https://treaties.un.org/Pages/Treaties. aspx?id $=4 \&$ subid $=$ A\&lang $=$ en

[accessed on 29 September 2014].

World Health Organization, 2002. "25 Questions \& Answers on Health \& Human Rights": Health and Human Rights Publication Series Issue, July 2002

World Health Organization, 2010. Commission on Information and Accountability for Women's and Children's Health http://www.who.int/woman_child_ac countability/about/coia/en/ [accessed on 29 September 2014].

World Health Organization, 2013. Women's and Children's Health: Evidence of Impact of Human Rights, Geneva.

World Health Organization, 20I4. WHO Constitution,

http://apps.who.int/gb/bd/PDF/bd47/EN/ constitution-en.pdf [accessed on 29 September 2014].

World Health Organization, 2014a. The work of WHO on health and human rights,

http://www.who.int/entity/hhr/HHRE TH_activities.pdf, [accessed on 29 September 2014].

World Health Organization Regional Office for Africa. Best practices in $\mathrm{IMCl}$ in the African Region. http://www.afro.who.int/en/clustersa-programmes/frh/child-and- 
African Population Studies Special Edition, 2015

adolescent-health/cahpublications.html [accessed on 29 September 2014].
Zimba E et al, 20I2. "Newborn survival in Malawi: a decade of change and future implications": Health Policy and Planning, 27 (Suppl 3): 88-I03. 